\title{
Playing with language, creating complexity: has play contributed to the evolution of complex language?
}

\author{
Michelle C Langley \\ Antonio Benítez-Burraco \\ Vera Kempe
}

This is the peer reviewed version of the following article:

Langley, M.C., Benítez-Burraco, A. \& Kempe, V. (2019) 'Playing with language, creating complexity: has play contributed to the evolution of complex language?', Evolutionary Anthropology.

which has been published in final form at https://doi.org/10.1002/evan.21810

This article may be used for non-commercial purposes in accordance with Wiley Terms and Conditions for SelfArchiving. 
Playing with Language, Creating Complexity:

Has Play Contributed to the Evolution of Complex Language?

Michelle C. LANGLEY ${ }^{1}$, Antonio BENÍTEZ-BURRACO², and Vera KEMPE ${ }^{3}$

1. Australian Research Centre for Human Evolution, Environmental Futures Research Institute, Griffith University, Australia. Email: m.langley@griffith.edu.au (Corresponding Author)

2. Department of Spanish, Linguistics, and Theory of Literature (Linguistics), Faculty of Philology, University of Seville, Spain. Email: abenitez8@us.es

3. Division of Psychology, School of Applied Sciences, Abertay University, Scotland, United Kingdom. Email: v.kempe@abertay.ac.uk 


\begin{abstract}
We argue that enhanced play may have contributed to the emergence of complex language systems in modern human (Homo sapiens). To support this idea, we first discuss evidence for an expansion of playing behavior connected to the extended childhood of modern human children, and the potential of this period for the transmission of complex cultural traits, including language. We then link two of the most important functions of play — exploration and innovation — to the potential for cumulative cultural evolution in general, and for emergence of complex language in particular. If correct, the shorter childhood of Neanderthals — involving restrictions on time to experiment and innovate may have restricted their language (and other symbolic) system/s. Consequently, fully investigating the role play may have had in the transmission of language and the development of symbolic cultures in both modern humans and Neanderthals provides a new avenue of research for Palaeolithic archaeology and related disciplines.
\end{abstract}

\title{
Keywords
}

Language Development; Symbolism; Childhood; Self-Domestication; Neanderthals.

\section{Running Title}

Play and the evolution of complex language 


\section{Author Biographies}

Michelle C. Langley is a ARC DECRA Research Fellow in the Australian Research Centre for Human Evolution at Griffith University, Brisbane, Australia. She specializes in traceological studies of osseous and shell technologies with her research revolving around the evolution of modern behavioral patterns.

Antonio Benítez-Burraco is molecular biologist and linguist, and an Associate Professor at the Department of Spanish, Linguistics, and Theory of Literature (Linguistics) at the University of Seville, Seville, Spain. He is interested in the biological underpinnings of human language, with a focus on language evolution and language disorders from a genetic and neurobiological perspective.

Vera Kempe is a cognitive psychologist specializing in language learning. She holds the Chair for Psychology of Language Learning at Abertay University in Dundee, Scotland. She uses experimental methods to investigate the interaction between human development, language learning, and language evolution. 


\section{Introduction}

Language is intimately linked to both cognition and culture. Complex languages are necessary to convey sophisticated meanings and for coordinating the rich social and cultural behaviors characteristic of humans today. By complex languages we mean representational and communicative systems endowed with all the features described by linguists for most present-day natural languages, particularly, the use of symbols for expressing concepts and the capacity to arrange symbols into elaborated compositional structures, which are mostly hierarchical and recursive, allowing users to convey a wide range of decontextualized meanings. These systems can be mastered by modern humans (Homo sapiens) because we are endowed with a species-specific cognitive faculty (commonly called faculty of language or language-readiness), but also because of the way in which we are reared and socialized. Thus, the complexity of modern languages rests on both cognitive and cultural factors so that, under certain socio-cultural circumstances (e.g., those underlying the creation of pidgins) or in cases of cognitive impairment (e.g., Down syndrome or some variants of Autism Spectrum Disorder), languages spoken by modern humans can be less complex.

Language does not fossilize. Our understanding of prehistoric languages therefore rests on three kinds of indirect evidence; (1) historical linguistics, (2) paleoanthropological remains, and (3) archaeological remains. In the first case, reconstruction of distant prehistoric languages is hindered by the existence of pervasive borrowing resulting from language contact, which erases most signals of shared ancestry beyond a fairly limited time frame. ${ }^{1}$ In the second case, while we may have remains of anatomical components that underpin the faculty of language, such as brain endocasts and speechrelated structures, their connection with specific features of languages (like phonology or morphology) is tenuous. ${ }^{2-3}$ And in the third case, inferences about cognitive capacity for language drawn from repertoires of symbolic material culture and complex technologies are problematic. ${ }^{4-7}$ As a consequence, all lines of evidence are limited in their ability to inform us about what types of languages were spoken by the earliest hominin communities throughout Eurasia. 
The most intense debate surrounding language abilities in deep history concerns the Neanderthal/modern human divide, not the least because these are the two species for which the most abundant paleogenetic, paleoanthropological, and archaeological evidence is available, but also because Neanderthals are the closest hominin species to ourselves. We now have a good understanding of the genetic and physiological differences between Neanderthals and modern humans. ${ }^{8-9}$ Furthermore, we have well-supported views of the distinctive cognitive and behavioral features of Neanderthals, including aspects of their culture. ${ }^{10}$ Still, different hypotheses exist regarding the linguistic abilities of Neanderthals and the emergence of modern languages of the kind typically found in present-day peoples. It is well beyond the scope of this paper to summarize this debate in detail (but see ${ }^{11-15}$ ). Instead, our aim here is to add a new piece to this complex puzzle, namely, to explore whether traceable differences in childhood playing behavior in late Pleistocene Neanderthal and modern human children may offer further insights into the character of the languages spoken by these two species.

\section{Self-Domestication and Complex Language Systems}

Speaking complex languages requires both having a language-ready brain and living in an appropriate cultural environment. Some of the genes selected in modern humans control skull/brain globularization, which may have facilitated the emergence of our apparently species-specific mode of thinking, and particularly, our language-readiness. As discussed in detail by Boeckx and BenítezBurraco $^{16}$, our skull/brain exhibits a more rounded shape compared to extinct hominins. Because a different brain shape entails a different brain configuration, our brain globularization can be hypothesized to have resulted in a rewiring that improved the connections between sub-cortical and cortical structures, habilitating the neuronal workspace needed for being able to transcend the signature limits of core knowledge systems, and ultimately, to combine and merge conceptual units 
that belong to distinct core systems, an ability that may underpin core combinatorial operations in natural language. Accordingly, the crucial step in the emergence of our language-readiness was not the emergence of the symbolic ability per se. After all, great apes, when properly trained, are able to learn and use symbols. ${ }^{17}$ Having a symbolic culture of the type already attested for in Neanderthals does not presuppose having a language-ready brain. Indeed, most, if not all, biological components of language are shared with other hominin species, including speech organs, leading to the conclusion that extinct hominins, and particularly, Neanderthals, had some sort of vocal communication system. ${ }^{15}$

At the same time, changes in brain structure and neural wiring resulting in language-readiness do not automatically imply the existence of modern-type languages. Instead, some of the features found in present-day languages arise from cultural evolution. The case of pidgins, mentioned above, which are structurally and functionally simplified languages that can emerge from language contact, but are spoken by neurotypical people, nicely exemplifies this view. Specifically, we argue that the social, cultural, and technological conditions that characterize modern human societies have exerted a pressure for more complex language. Greater social and technological complexity necessitates greater and more context-independent and reliable information transmission, which can be achieved through larger vocabularies and more learnable and informative morphosyntax. Without this pressure, languages are expected to exhibit reduced vocabularies and less semantic transparency, with abundance of idioms and idiosyncratic speech, as well as reduced compositional structure. ${ }^{18}$

We further argue that human self-domestication, i.e., the adaptation to an ecological niche created by modern humans themselves involving reduced exposure to predation and more consistent food supply that resulted in a relaxation of selection pressures for aggression, was one of the factors that facilitated the emergence of more complex languages via a process of cultural evolution. The arguments for a relationship between (self-)domestication and the emergence of language complexity ${ }^{19}$ rest on 
observations of domesticated birds like the Bengalese finch displaying more complex song patterns, as well as on domesticated mammals like dogs displaying evidence for communicative inference traits not found in their wild counterparts. ${ }^{20-21}$ Interestingly, in mammals, selection for tameness results in the so-called "domestication syndrome", which is assumed to arise as a consequence of the relaxation of certain selection pressures. This syndrome entails a range of specific physical, cognitive, and behavioral traits, including a prolonged juvenile period (neoteny), reduced reactive aggression, a longer socialization window, changes in the craniofacial area affecting the ears, face, and dentition, as well as reduced brain capacity. ${ }^{22-23}$ These characteristics distinguish not just domesticated animals from their wild counterparts, but also modern humans from wild primates and extinct hominins such as Neanderthals - hence the hypothesis of modern humans as self-domesticated hominins because, unlike other animals, humans were not domesticated by any external agent. Instead, modern humans have been subject to selection for enhanced socialization in response to environmental changes and increasing population densities ${ }^{24}$, bringing about features similar to those found in domesticated animals. In both cases, in-group aggression appears to be attenuated, which induces a reduced physiological response of the aggression mechanisms that promotes the constellation of traits characteristic for the domestication syndrome. As noted by Cieri and colleagues, ${ }^{25}$ one of the factors fueling human cultural evolution, and the emergence of what has previously been called "behavioral modernity", is the increased level of social tolerance and increased pro-sociality that enabled denser social networks and increased social complexity in modern humans ${ }^{26-27}$, which ultimately resulted from reduced aggression via reduction in average androgen reactivity, a hallmark of domestication. Such "behavioral modernity" likely entailed a complex interplay between alloparenting, teaching, play, and language use, which, in turn, will have impacted and consolidated the underpinning social and biological conditions such as increased group size and extended childhood. Our specific claim here is that as human self-domestication facilitated the emergence of more complex languages, changes in playing behavior played an important role in the construction of this language-friendly cultural niche. Because this development may have opened up the possibility for co-evolution via 
multiple feedback mechanisms, complex languages, in turn, are expected to have affected human cognition and its underlying neurobiology. It has been suggested that these processes took place 100$50 \mathrm{kya},{ }^{28-29}$ well after the split from Neanderthals, which renders comparisons of archaeological evidence between modern humans and Neanderthals particularly informative (Figure 1).

\footnotetext{
** FIGURE 1 ABOUT HERE **
}

\section{Social complexity in the Paleolithic}

Our line of argument suggests that the social and technological conditions that favor more complex languages emerged in modern humans only recently, as our self-domestication progressed, and are not necessarily present in Neanderthals. This suggestion is supported by the fact that Middle Paleolithic Neanderthal populations are argued to have been smaller and more widely dispersed than Upper Paleolithic modern human populations, with the latter maintaining significantly larger social networks. ${ }^{30-31}$ Neanderthals had estimated group sizes of up to around 25 individuals, and are commonly argued to have interacted largely on a 'face-to-face' basis, likely personally knowing every individual in their social network. ${ }^{32}$ Indeed, genetic evidence supports the idea that Neanderthal groups were interacting with familiar individuals within family units, as supported by the practice of patrilocal mating behavior. ${ }^{33}$

Not only were modern human groups significantly larger than those of Neanderthals, but they also appear to have been composed quite differently: the increased life expectancy and proposed shorter birth spacing intervals of modern humans potentially resulted in considerably more infants, young children, and elders forming part of the community. ${ }^{34}$ The presence of numerous elders, in turn, may have resulted in the potential adoption of more clearly defined sex-related roles, ${ }^{35}$ as well as the potential adoption of grandmaternal alloparenting, which played an important role in inclusive fitness by contributing towards the health of weaned, yet not fully self-sufficient young. ${ }^{36}$ In contrast, it has 
been suggested that Neanderthals may have spent most of their adult lives as undifferentiated equals. $^{37}$

If Neanderthal population densities were so low that macro-bands (the conglomeration of several smaller groups who inhabit a set region and regularly interact) only periodically came into contact with one another through social networks (for example to exchange mates, information, or goods), an extensive symbolic material culture which transmitted a multitude of information would certainly not have been required. ${ }^{38-39}$ The greater and more diverse social networks of modern humans, on the other hand, may have exerted pressure for more complex artifacts and for language to enable contextindependent transmission of technological and social information between less connected individuals and groups - a situation that, among other things, promotes order and structure of material and cognitive elements, and necessitates larger vocabularies and longer, more complex utterances. ${ }^{39}$ If language is to carry more novel information beyond the 'Here and Now', this situation may have exerted a pressure for more complex morpho-syntax to organize the increased semantic complexity and informativeness.

\section{Learning Complex Languages: The Role of Childhood}

Our line of argument also suggests that self-domestication not only facilitated the social and cultural conditions that created pressures for more complex language, but also facilitated developmental changes that allowed modern humans to transmit such complex language to their offspring. One such change is the emergence of an extended juvenile period and the associated expansion of parenting and alloparenting behaviors, favored by the reduction in-group aggression brought about through self-domestication. ${ }^{40}$ This change is crucial, as far as mastering a more complex language demands more teaching by caregivers and more learning by children. To better understand the role of childhood 
in the emergence of language complexity, we want to specifically focus on the differences in childhood between modern humans and Neanderthals.

Just like modern human children, Neanderthal children arrived vulnerable and underwent significant brain growth as they matured. ${ }^{41-42}$ Skeletal remains suggest that both Neanderthal and modern human infants entered the world surrounded by essentially the same risks to themselves and their mothers during birthing, and both lived physically challenging lives. While it was originally thought that Neanderthals faced far higher risks of significant injury or death, ${ }^{43}$ recent reassessments of these data found no support for this suggestion, ${ }^{44}$ and there is increasing evidence for self-care (medications), as well as the care of the sick and injured for months to years. ${ }^{45-46}$

However, juvenile mortality seems nonetheless to have been greater in Neanderthal populations than in modern human, with juveniles comprising 43 per cent of northern Eurasian Neanderthal fossils, as opposed to less than 30 per cent for modern humans. ${ }^{47}$ Overall, modern human juveniles appear to have experienced less stress during their childhood than did Neanderthal children. While it remains debated whether significant differences in the rate of maturation to adulthood were experienced between Neanderthals and modern humans ${ }^{48-50}$ it appears that patterns of Neanderthal biological and cognitive growth are subtly different from those of contemporary and later modern humans. It has even been debated whether Neanderthals had a 'childhood' at all. ${ }^{51}$

Specifically, analysis of teeth suggests that Neanderthals reached adulthood at around 15 years of age, ${ }^{52}$ which is somewhat faster than the age of biological adulthood assigned to modern humans. ${ }^{42,50}$ It appears that the Neanderthal brain also grew faster than that of a modern human child, beginning around $400 \mathrm{~cm}^{3}$ and tripling in volume by age three before reaching an adult volume of around 1500 $\mathrm{cm}^{3}{ }^{53}$ Differences also appear in the specific patterns of brain growth and expansion. ${ }^{54}$ Neanderthal brain shape developed without the pronounced globularization phase of modern humans described 
above, which is thought to be associated not only with subtle differences in perception, ${ }^{3,42,53}$ but also in connectivity patterns important for language processing. ${ }^{16}$

The small group size and possible lack of elders mentioned above has implications for social aspects of Neanderthal childhood, including peer group development, time for "free play", and availability of teachers. ${ }^{44}$ For example, peer-peer play, which is common amongst the Great Apes, and contributes to normal social development in the young, even where parental play is lacking, ${ }^{55}$ may have been less diverse or numerous as that experienced by contemporary modern human children owing to the differences between the communities outlined above.

It should be pointed out that small group sizes do not preclude periodic aggregations of larger groups of Neanderthals. ${ }^{56-57}$ In particular, Hayden suggested that such gatherings could have ranged from 50 people (2-3 local bands) to several hundred people (10-20 local bands). ${ }^{56}$ If such aggregations of Neanderthal bands did occur, these larger groups may have constituted cultural (or even linguistically) distinct groups of perhaps up to 200 individuals who preferentially interacted. Based on observations from extant hunter-gatherers, it was found that children are under less strict supervision in such situations, ${ }^{58}$ and it might therefore be argued that Neanderthal children may have had some opportunity "to be kids" and indulge in more modern patterns of play during such group gatherings. If this unsupervised play did occur on regular (if rare) occasions, then we should expect a burst of learning amongst Neanderthal children at these times.

Hawcroft and Dennell ${ }^{59}$ have argued that if Neanderthals spent less time as juveniles, both relatively and absolutely compared to modern humans, learning the prerequisite technological and social skills for adult life would have required the adoption of directed instructional learning, where subadults acquire existing knowledge from imitating their elders, rather than through exploratory, experiencebased learning. The suggested technological stasis, relative to modern humans, in Neanderthal tool 
production, ${ }^{60}$ can be taken as further evidence for the predominance of imitation rather than innovation in social learning. Initially, such imitation is assumed to have been carried out with the aim of retaining functional characteristics of tools and artifacts, rather than their normative value as tribal markers or their social-affiliative potential for creating shared experience. Such functionally oriented imitation was likely based on a behavioral strategy to over-imitate to conserve cognitive resources by automatically copying all actions that could be identified as intentional. ${ }^{61}$ This way, Neanderthal children would have received knowledge which was a carbon copy of knowledge acquired by their parents, who, in turn, would have copied this knowledge from the previous generation, and so on. Acquiring knowledge in this manner would have disposed children against challenging the given wisdom, owing to the short amount of time available for learning the large amount of cultural information that must be absorbed. Thus, learning by imitation would reign supreme.

Imitation ensures transmission of cultural traits like tools for which all actions involved in production and usage are overtly accessible to the learner's observation, regardless of the causal status of those actions (i.e., whether they are functionally relevant or not). Unlike teaching, imitation focusses the learner's emphasis on observable characteristics of a transmitted cultural trait, and, consequently, limits room for the introduction of innovations, be they functionally or socially motivated. If one faithfully copies just the actions required for tool production, without receiving explanations and without a resulting understanding of the functional purpose of the outcome of such actions, then it is difficult to deviate from the target action in ways that enhance the structural and functional characteristics of the end product. Yet with respect to tool and object use, modern human children have a unique propensity for hypothesis testing and exploration. ${ }^{62-64}$. Similarly, while imitation may be sufficient for transmission of vocal communication systems with limited hierarchical structure (e.g., birdsong), it is insufficient to transmit the functional characteristics of communication systems with more complex structure. Below we will explore to what extent play may enhance the acquisition 
and transmission of language as a complex system that comprises non-overt rules and representations ${ }^{65-66}$.

\section{Learning Complex Languages: The Role of Play}

The social niche generated through self-domestication may have created conditions for enhanced play, ${ }^{66}$ which, in turn, may have served as a further catalyst for the emergence of complex language. Playing behavior has previously been used as a proxy for symbolic abilities in late Pleistocene populations. ${ }^{67-69}$ While the concept of play arguably comprises heterogeneous behaviors for which commonalities are difficult to define, ${ }^{70}$ a range of playing behaviors undoubtedly exists in animals, who do not have language, and hence also must have existed in early hominins. However, a reduction of stress-inducing pressures such as predation, increased continuity of food supply, and larger group size associated with self-domestication ${ }^{71}$ may have paved the way for more frequent and perhaps qualitatively different play. We suggest that a range of play activities may have had the potential for boosting complex language, along two avenues: First, increased child play during an extended childhood can support language development thereby facilitating language transmission. Secondly, the propensity for play cemented during childhood facilitates playful linguistic innovations introduced by adolescents and adults. Such innovations can be transmitted horizontally via social networks, especially in adolescence, but also vertically from parents to offspring of the next generation, thereby consolidating their place in the emerging structural characteristics of complex language.

Symbolic, pretend, and mental (also called fantasy) play (what Burghardt ${ }^{70}$ terms 'tertiary process play' that does not require overt behavior) involves nonliteral action and is, according to Lillard, ${ }^{72}$ an evolved behavior, as it universally emerges according to a fixed schedule. Like language, pretend and symbolic play relies on the representational capacity to use a signifying entity to stand for another 
entity. It has connections to cognitive and social skills that are important for language development, such as symbolic thinking, theory of mind, and counterfactual reasoning. ${ }^{73,74}$

These shared cognitive mechanisms between play and language that arise from common ontogenetic roots and joint representational demands may contribute to how play can influence language development and drive the emergence of further linguistic complexity. ${ }^{75-76}$ Thus, in infants from modern Western societies, initiation of babbling and single-object play occurs around the same time, towards the end of the first year of life. Moreover, both play and language share a computational/motor dimension: playing behavior entails the planning and execution of motor sequences, while sentence construction involves the arrangement of symbolic units (words) following a set of rules (grammar). Over the course of development, these precursors to play and language grow into complex abilities: the motor control required for single object reach subsequently drives the motor control that underpins more complex playing and verbal behavior, ${ }^{77}$ hence the hypothesis that the sequencing ability involved in tool-making might have constituted a precursor of the ability to produce complex grammar (the 'technological hypothesis').

In addition to sharing common origins, language and play can also be mutually supportive behaviors. ${ }^{80-82}$ While functional play only correlates with expressive language, symbolic play, in which children make substitutions and transfer between objects and actions, significantly correlates with both expressive and receptive language. ${ }^{83}$ This link between symbolic play and language development has recently been confirmed through meta-analytical evidence. ${ }^{82}$ Symbolic play can support language acquisition indirectly and directly. The indirect support comes from the opportunity for the developing child to gain language exposure and language practice. Play promotes joint attention, and adult play partners provide more and higher-quality language input as coordination of roles and symbolic meaning need to be negotiated. 
Another way in which symbolic play can support language development is when language serves as the object of play, allowing children to explore a variety of uses of speech sounds and linguistic structures. These opportunities arise when language stands in as a substitute for activities executed in the context of symbolic play, for example, when a child says 'wash-wash-wash' to indicate the symbolic act of washing. ${ }^{80}$ Moreover, many social play activities require verbal negotiation of how the play is to be organized and what its content will be, both between adults and children as well as between children themselves ${ }^{84}$. To make elaborate symbolic and other forms of play possible, playmates need to agree their different roles and the rules of engagement thus making language an important means by which the goal of play can be achieved. This negotiation, in turn, is a further avenue by which play becomes a catalyst for using language to convey shared meaning.

The second avenue along which play can boost language comes from playful language use by adolescents and adults. This involves enhancement of language development through playful language use and scaffolding that adult caregivers often employ with children, both in spontaneous and conventionalized ways. Spontaneous playful language use can serve to share emotional states and to control infant arousal states. ${ }^{85}$ Furthermore, in some languages, certain aspects of playful language scaffolding became conventionalized in child-directed speech registers. For example, Russian mothers addressing their children often use diminutives and simple forms of nouns interchangeably in close proximity within the same conversational episode without apparent semantic function. ${ }^{86}$ Such diminutive 'word-play' exposes the morphological structure of Russian nouns by emphasizing the stability of stems in the face of inflectional variation, as if trying to demonstrate where in the word stems end and inflections begin. Using diminutives in this way can aid morphology acquisition not just by highlighting the distinction between referential and grammatical parts of the form but also because diminutives tend to regularize and simplify certain morphological cues, e.g., gender affixes or case markers. ${ }^{87}$ 
Even more direct support of language development comes from adults' playful child-directed verbal activities like nursery rhymes and songs which, through their highly structured form, enhance implicit and explicit learning of complex grammatical properties of the language, such as noun class membership, or declension and conjugation paradigms. ${ }^{88}$ The melodic contours found in children's songs increase emotional engagement and capture the learner's attention while its rhythmic properties enhance short-term recall and draw attention to specific properties of the input such as inflectional or syntactic gender cues. ${ }^{89-90}$ In general, input that is playfully structured may provide near optimal levels of complexity that capture attention without overwhelming the child. ${ }^{91}$

These examples of positive links between various forms of play and language development align well with the idea that the primary function of play is to practice and hone abilities, in this case, language abilities, that are important for survival, ${ }^{92}$. Thus, play in its various forms may provide opportunities for enhancing the outcomes of learning mechanisms like exemplar-based statistical learning and analogy generation that allow children to extract semantic and grammatical knowledge from the input. ${ }^{62,93-94}$ However, acquiring language also involves inferring correct forms of syntactic constructions which are not present in the input. ${ }^{63}$ Consequently, part of language acquisition entails entertaining hypotheses about how to generalize beyond the evidence. In the domain of object manipulation and tool use, Gopnik and colleagues have proposed that, because they are unencumbered by prior knowledge, children have greater innovative propensity than adults allowing them to consider a wider range of less plausible hypotheses. ${ }^{64-66}$ Several scholars have emphasized the potential of play for such hypothesis testing. ${ }^{66,95-96}$ However, children's innovative potential is more apparent in the acquisition of instrumental skills rather than social conventions. ${ }^{97}$ Because language is a social convention, and children are faithful imitators of social conventions, ${ }^{97}$ it is doubtful that children are the primary agents of linguistic innovation and language change. ${ }^{98-100}$ 
Instead, we argue that a propensity for playful innovation that has been cemented with respect to tools and objects during childhood reaches into adolescence and adulthood, where it may provide one engine for linguistic innovation and change that has allowed language to accommodate the complex social conditions made possible by self-domestication. As argued above, to extend playing behavior into adulthood is one of the hallmarks of domestication. In modern humans, play is not just a pursuit of the young but a lifelong behavior. If longer childhoods have enabled more play over the course of self-domestication, then play itself may have become a learned activity that is carried into adolescence and adulthood. As a result, modern human adolescents and adults are able to engage in playful exploration of novel uses of words and constructions and novel ways to combine them. Such play, then, may have the potential to modify linguistic structure by providing the impetus for innovation that underlies the emergence of complex structure during cultural transmission. Moreover, this potential for innovation can manifest itself through artistic and aesthetic proclivities, which can support linguistic innovations that drive complex languages. Some bioaesthetic proposals view art as an expression of a sense of order, which comprises "production and appreciation of regularity, symmetry, and patterns" or what Fitch termed "dendrophilia". 39,101 This propensity for cognition to be guided by tree-like hierarchical structures manifests itself in many domains such as ornaments, crafts, visual art, and music, and may act as a driver not just for cultural evolution in various artistic domains, but also in non-artistic domains like tool production and language.

Typological surveys of world languages as well as accounts of language change suggest that there is evidence for aesthetically motivated aspects of language structure, which has been hypothesized to accommodate two opposite forces that are functional by nature ${ }^{102}$ : the ease of production effort (the speaker's goal) and the maximization of comprehensibility (the hearer's goal). Speakers tend to minimize and simplify linguistic structures following a principle of economy, whereas hearers prefer to minimize what must be inferred from the context and thus expect speakers to be as prolix as possible in order to optimize parsing. Nonetheless, some structural aspects of languages seem not to 
obey these two opposite functional constraints. For example, in the case of so-called "decorative morphology" similar sounding inflectional endings are spread across many parts of the sentence in languages with long-distance agreement, like Russian adjective and noun endings (e.g., v nashikh starykh gorodakh 'in our old cities'). Notice that this type of agreement can be viewed as a nonfunctional feature, provided that many languages only mark the syntactic function on the head of phrases or do not mark any component at all, like Chinese. Likewise, Khmer sentences contain considerable amounts of redundant and servant words with no clear referential roles (e.g., papuh teuk pruac pruac 'water keeps bubbling and bubbling', literally, 'bubble water bubble.up bubble.up'). Some authors have suggested these nonfunctional features of languages are aesthetically motivated and might result from a pervasive human proclivity for structure and order like rhymes, alliterations, sound plays, formal symmetry, and the like, which may have found their ultimate expression in recent sound-poetic styles like Zaum or Dadaism. ${ }^{103}$

\section{Play in Pleistocene Modern Humans and Neanderthals}

Given that domestication increased play behavior in animals, ${ }^{104-105}$ we suggest that play became a more prominent activity in modern humans as features of domestication increased in our species. As noted above, we make this assumption because self-domestication is associated with a reduction in stress hormones due to relaxed selection pressures (e.g., from predation, variation in food supply) ${ }^{71}$ connected to the advantages of larger group sizes. Larger group size, in turn, provides more opportunities for play through increased protection and a ready supply of playmates (peer-peer play). As will be seen below, testing this hypothesis is currently difficult as identifying the activities of children in Pleistocene contexts remains in its infancy, though the currently available evidence does lend some support to our suggestions.

As there is evidence for chimpanzee young using sticks as dolls, ${ }^{106}$ we can be confident that there is a long ancestry of object (but not necessarily symbolic) play in primates, and consequently, that 
Neanderthal playthings should exist in some form (Box 1). To find these objects, one first thinks of turning to those contexts from which Neanderthal children are best known: their skeletal remains. Burials of fetus', infants, and older children throughout the Neanderthal territories have been found to include items which may be grave goods, though the identification of materials as such remains contentious. However, even if these items are legitimate grave offerings, interpreting any of them as children's playthings or tools — and consequently, using them to investigate Neanderthal play behavior — is highly problematic as their inclusion in the grave may have more to do with adult thought patterns than those of the child in question. ${ }^{107}$

\section{** FIGURE 2 ABOUT HERE **}

Outside of burial contexts, only one artifact has been tentatively identified as a Neanderthal toy - a $4.4 \mathrm{~cm}$ long handaxe recovered from Rhenen, Netherlands. ${ }^{108}$ This identification is based on the small size of the tool. Apart from this single case, the only currently available evidence for the activities of Neanderthal children comes in the form of the transmission of flintknapping knowledge. For example, Bodu identified three levels of flintknapping skill within the Châtelperronian levels of Arcy-sur-Cure (France), ${ }^{109}$ including not only evidence for skills displayed by experts, but also for skills of advanced learners and one or two artifacts that originate from beginners. These beginners are most likely to be children since flintknapping (and other tool-making traditions) requires the acquisition of advanced cognition and motor skills to achieve good results, and so training should start early in life. Similarly, Stapert identified children's knapping through high percentages (86 per cent) of cores showing hinges, steps, face battering, and stacked steps at Site K, Maastricht-Belvédère, Netherlands. ${ }^{108}$ Stacked steps are indicative of pointless and frustrated battering of a spot where flaking cannot be achieved, and is rarely produced by expert knappers, yet these traces appear on 59 per cent of the cores at the site. Several unusual artifacts from another Dutch site, Rhenen are also interpreted as the work of children attempting to replicate advanced tool forms. ${ }^{108}$ Stapert argues that these artifacts 
suggest a transmission pattern by which children were not only taught various techniques but also had the opportunity to mimic adult behavior - supporting the notion that Neanderthal children learned through imitation rather than exploration.

In regards to other forms of material culture, Spikins et al. (p128) has suggested that "symbolic objects [may have played] a distinctive internal role, one perhaps more focused on the involvement of children" $" 44$ a suggestion supported not only by child psychology which notes the importance of toys for enhancing learning in play, ${ }^{66}$ but also by a recent study of recent hunter-gatherer children's playthings. ${ }^{58}$ This last study found that items typically classified by archaeologists as 'symbolic' in character (figurines, ornaments, musical instruments, miniatures), are heavily linked to children's activities in modern hunter-gatherer communities. ${ }^{58}$ In other words, children's material culture has likely been hiding in plain sight all along and we now need to further investigate these possibilities to elucidate the role of children in their respective prehistoric communities. Along these lines, the notable quantitative and qualitative differences between the symbolic material culture records of Neanderthals and contemporary/near contemporary modern humans come into play, because if figurines (for example) are an important part of child development activities (symbolic play), the lack of such items in Neanderthal contexts suggests that these hominins were not capable of "human-grade fantasy play" (p87) with implications for their cognitive plasticity. ${ }^{69}$ Furthermore, if Neanderthal children did not engage in such developed fantasy play, then the characteristics of their playthings (for they should still exist in some form) could be pronouncedly different to what we would recognize as 'toys' making the job of the archaeologist even more difficult.

Turning to evidence related to modern human children, a search of the archaeological and palaeoanthropological literature found that those who grew up outside of Eurasia/Northern Asia during the Late Pleistocene remain almost entirely invisible. Indeed, even within the intensely studied Palaeolithic European context, concrete evidence surrounding the activities of children during life 
(that is, outside of their graves) remains elusive. In more recent times, art has been useful for identifying children's material culture and activities, though we are not so fortunate for the early periods of which we are speaking here, even amongst the rich corpus of Western European Palaeolithic art. ${ }^{110-111}$

Indeed, identifying child activity areas in the Pleistocene record is an aspect of childhood archaeology still to be developed, though child-sized footprints in the clay and sand floors of decorated caves ${ }^{112}$ as well as finger flutings made by children in their soft walls ${ }^{113}$ have been identified. In these cases, it is debated whether young children were either brought into such locations for social or cultural occasions ${ }^{114}$ or that they simply played in these areas as part of youthful exploration. ${ }^{115}$ Footprints of children found outside of such protected areas are rare, and while examples do occur, as far as we are aware, any such traces are yet to be examined to determine the activities of the child who made them.

Therefore, and as is the case for Neanderthals shown above, the realm of modern human childhood we known most about is the transmission of craft knowledge. Again, most commonly explored in lithic studies, ${ }^{116-117}$ recent work has also identified apprentice artists. ${ }^{68,118-119}$ The items which might, arguably, be the most informative regarding the playing patterns of children in different communities

— playthings — remain elusive, though recent work in this area is opening up possibilities, ${ }^{58,66,111}$ and early indications (specifically, the presence of human and animal figurines within Upper Palaeolithic contexts) support the presence of symbolic or fantasy play amongst Palaeolithic modern human children.

\section{Conclusions}

In this paper, we have argued that one mechanism which lead to increased language complexity was play and highlighted how this behavior supports language acquisition in children and may boost 
linguistic innovation in adolescents and adults. In support, we point to evidence for mainly imitative learning of tool production and tool use in Neanderthals, which may explain conservation of cultural traits over significant time periods, and that learning by imitation may have extended to vocal communication making highly compositional language systems in Neanderthals unlikely. We argued that, like many complex cultural traits, the emergence of complex language comprising extensive reference and compositional structure used by modern humans required extensive learning and innovation, and that childhood play may support this learning process and also lay the foundations for a life-long propensity for play, so that language complexity may have been facilitated by playful scaffolding and aesthetically motivated innovations.

Of course, many of these suggestions are fairly speculative at this point, supported by circumstantial evidence at best. In order to bolster the argument that playing behavior may have had a role in cultural evolution in general, and in the emergence of complex language specifically, several lines of evidence will need to be scrutinized further. First, we need archaeological evidence that can provide quantitative comparisons between Neanderthals and modern humans in terms of character and frequency of playthings, from which we might be able to deduce the relative prominence of play in these two species. Second, we need evidence from cultural evolution experiments in the laboratory, specifically iterated language learning experiments, which incorporate play into the transmission process to see whether it can support learning of complex compositional signaling systems and, thus, further drive the emergence of language complexity. Third, we need clear assumptions about the nature of play to model its crucial functional elements in Bayesian and agent-based simulations of language learning and language transmission to further explore its role in cultural evolution. Finally, we need more diverse and richer comparative evidence, including genetic studies with deep homology analyses, involving animals but also cognitive disorders impacting on socialization and language behavior, to learn more about the effect of cognitive constraints on play and its role in the emergence of complex language. 
In conclusion, while play is certainly not the only game in town ${ }^{19}$, we hope to have highlighted that this behavior, which has deep evolutionary origins, should be scrutinized more carefully for its potential role in cultural transmission and development of language.

\section{Acknowledgements}

Parts of this research was funded by the Spanish Ministry of Economy and Competitiveness (Grant FFI2016-78034-C2-2-P [AEI/FEDER, UE] to ABB).

\section{Data Availability}

The data that supports the findings of this study are found in the references cited herein.

\section{References}

[1] Nichols J. 1997. Modeling ancient population structures and movement in linguistics. Annu Rev Anthropol 26: 359-384.

[2] Fitch WT. 2000. The evolution of speech: A comparative review. Trends Cogn Sci 4: 258-267.

[3] Pearce E, Stringer C, Dunbar RIM. 2013. New insights into differences in brain organization between Neanderthals and anatomically modern humans. Proc R Soc B Biol Sci 280: 1-7.

[4] d'Errico F, Henshilwood C, Lawson G, et al. 2003. Archaeological evidence for the emergence of language, symbolism, and music - An alternative multidisciplinary perspective. J World Prehist 17: $1-70$. 
[5] Stout D, Chaminade T. 2012. Stone tools, language and the brain in human evolution. Phil Trans R Soc B Biol Sci 367: 75-87.

[6] Putt SS, Woods AD, Franciscus RG. 2014. The role of verbal interaction during experimental bifacial stone tool manufacture. Lithic Technol 39: 96-112.

[7] Cataldo DM, Migliano AB, Vinicius L. 2018. Speech, stone tool-making and the evolution of language. PLoS ONE 13: e0191071.

[8] Sommel M, Liu X, Khaitovich P. 2013. Human brain evolution: transcripts, metabolites and their regulators. Natl Rev Neurosci 14: 112-27.

[9] Stringer C. 2016. The origin and evolution of Homo sapiens. Phil Trans R Soc B Biol Sci 371: 20150237.

[10] Johansson S. 2014. The thinking Neanderthals: What do we know about Neanderthal cognition? Wiley Interdisc Rev Cogn Sci 5: 613-620.

[11] Davidson I, Noble W. 1989. The archaeology of perception. Traces of depiction and language. Curr Anthropol 30: 125-155.

[12] Wynn T. 1991. Tools, grammar and the archaeology of cognition. Camb Archaeol J 1: 191-206.

[13] Knight C, Studdert-Kennedy M, Hurford J. 2000. The evolutionary emergence of language: Social function and the origins of linguistics. Cambridge: Cambridge University Press. 
[14] Johansson S. 2015. Language abilities in Neanderthals. Ann Rev Ling 1: 311-332.

[15] Dediu D, Levinson SC. 2018. Neanderthal language revisited: Not only us. Curr Opin Behav Sci 21: 49-55.

[16] Boeckx C, Benítez-Burraco A. 2014. The shape of the human language-ready brain. Front Psychol 5: 282.

[17] Beran MJ, Heimbauer LA. 2015. A longitudinal assessment of vocabulary retention in symbolcompetent chimpanzees (Pan troglodytes). PLoS ONE 10: e0118408.

[18] Benítez-Burraco A, Kempe V. 2018 The emergence of modern languages: Has human selfdomestication optimized language transmission? Front Psychol 17: 551.

[19] Thomas J, Kirby S. 2018. Self-domestication and the evolution of language. Biol Philo 33: 9.

[20] Takahasi M, Okanoya K. 2010. Song learning in wild and domesticated strains of whiterumped munia, lonchura striata, compared by cross-fostering procedures: Domestication increases song variability by decreasing strain-specific bias. Ethology 116: 396-405.

[21] Kaminski J, Tempelmann S, Call J, et al. 2009. Domestic dogs comprehend human communication with iconic signs. Dev Sci 12: 831-837.

[22] Wilkins AS, Wrangham RW, Fitch WT. 2014. The "domestication syndrome” in mammals: a unified explanation based on neural crest cell behavior and genetics. Genetics 197: 795-808. 
[23] Sánchez-Villagra MR, Geiger M, Schneider RA. 2016. The taming of the neural crest: A developmental perspective on the origins of morphological covariation in domesticated mammals. $\mathrm{R}$ Soc Open Sci 3: 160107.

[24] Powell A, Shennan, S. Thomas MG, 2009. Late Pleistocene demography and the appearance of modern human behavior. Science 324: 1298-1301.

[25] Cieri RL, Churchill SE, Franciscus RG, et al. 2014. Craniofacial Feminization, Social Tolerance, and the Origins of Behavioral Modernity. Curr Anthropol 55: 419-443

[26] Sinha C. 2015. Ontogenesis, semiosis and the epigenetic dynamics of biocultural niche construction. Cogn Dev 36: 202-209.

[27] Fogarty L, Creanza N. 2017. The niche construction of cultural complexity: Interactions between innovations, populations size and the environment. Phil Trans R Soc B Biol Sci 372: 20160428.

[28] Boeckx C, Benítez-Burraco A. 2015. Osteogensis and neurogenesis: A robust link also for language evolution. Front Cell Neurosci 9: 291.

[29] Benítez-Burraco A, Boeckx C. 2015. Possible functional links among brain- and skull related genes selected in modern humans. Front Psychol 6: 794.

[30] Féblot-Augustins J. 1997. La circulation des matières premières au Paléolithique. Liège: ERAUL. 
[31] Gamble C. 1999. The Palaeolithic societies of Europe. Cambridge: Cambridge University Press.

[32] Conard NJ. 2011. The demise of the Neanderthal cultural niche and the beginning of the Upper Paleolithic in Southwestern Germany. In: Conard NJ and Richter J, editors. Neanderthal lifeways, subsistence and technology: One hundred fifty years of Neanderthal study. London: Springer. p 223240.

[33] Lalueza-Fox C, Rosas A, Estalrrich A, et al. 2010. Genetic evidence for patrilocal mating behavior among Neandertal groups. Proc Nat Acad Sci 108: 250-3.

[34] Skinner M. 1997. Dental wear in immature Late Pleistocene European hominines. J Archaeol Sci 24: 677-700.

[35] Kuhn SL, Stiner MC. 2006. What's a mother to do? The division of labor among Neandertals and humans in Eurasia. Curr Anthropol 42: 953-980.

[36] Hawkes K, O’Connell JF, Blurton Jones NG. 1997. Hadza women's time allocation, offspring provisioning, and the evolution of long postmenopausal life spans. Curr Anthropol 38: 551-577.

[37] Pettitt P. 2000. Neanderthal lifecycles: Developmental and social phases in the lives of the last archaic. World Archaeol 31: 351-366.

[38] Langley MC. 2013. Storied landscapes make us (modern) human: Landscape socialisation in the Palaeolithic and consequences for the archaeological record. J Anthropol Archaeol 32: 614-629. 
[39] Westphal-Fitch G, Fitch WT. 2018. Bioaesthetics: The evolution of aesthetic cognition in humans and other animals. Prog Brain Res 237: 3-24.

[40] Bogin B. 1999. Evolutionary perspectives on human growth. Ann Rev Anthropol 28: 109-153.

[41] Ponce de León M, Golovanova L, Doronichev V, et al. 2008. Neanderthal brain size at birth provides insights into the evolution of human life history. Proc Nat Acad Sci 105: 13764-8.

[42] Neubauer S, Hublin J-J. 2012. The evolution of human brain development. Evol Biol 39: 56886.

[43] Berger TD, Trinkaus E. 1995. Patterns of trauma amongst the Neanderthals. J Archaeol Sci 22: 841-92.

[44] Spikins P, Hitchens G, Needham A, et al. 2014. The cradle of thought: Growth, learning, play and attachment in Neanderthal children. Oxf J Archaeol 33: 111-134.

[45] Hardy K, Buckley S, Collins MJ, et al. 2012. Neanderthal medics? Evidence for food, cooking, and medicinal plants entrapped in dental calculus. Naturwissenschaften 99: 617-26.

[46] Weyrich LS, Duchene S, Soubrier J, et al. 2017. Neanderthal behavior, diet, and disease inferred from ancient DNA in dental calculus. Nature 544: 357-361.

[47] Soffer O. 1994. Ancestral lifeways in Eurasia — The Middle and Upper Paleolithic Records. In: Nitecki MH and Nitecki DV, editors. Origins of Anatomically Modern Humans. Boston: Springer. p 101-119. 
[48] Guatelli-Steinberg D, Reid DJ, Bishop TA, et al. 2005. Anterior tooth growth periods in Neandertals were comparable to those of modern humans. Proc Nat Acad Sci 102: 14197-202.

[49] Macchiarelli R, Bondioli L, Debenath A, et al. 2006. How Neanderthal molar teeth grew. Nature 444: $748-51$.

[50] Smith TM, Tafforeau P, Reid DJ, et al. 2010. Dental evidence for ontogenic differences between modern humans and Neanderthals. Proc Nat Acad Sci 107: 20923-8.

[51] Nelson, M. 2012. Imitation, pretend play, and childhood: Essential elements in the evolution of human culture. J Comp Psychol 126: 170-181.

[52] Ramiez-Rossi FV, Bermudez de Castro JM. 2004. Surprisingly rapid growth in Neanderthals. Nature 428: 936-9.

[53] Zollikofer CPE, Ponce de León MS. 2013. Pandora's growing box: inferring the evolution and development of hominin brains from endocasts. Evol Anthropol 22: 20-33.

[54] Gunz P, Neubauer S, Maureille B, et al. 2010. Brain development after birth differs between Neanderthals and modern humans. Curr Biol 20: 921-922.

[55] Spijkerman RP, van Hoof JA, Dienski H., et al. 1997. Differences in subadult behaviors of chimpanzees living in peer groups in a family group. Int J Primatol 18: 439-454.

[56] Hayden B. 2012. Neanderthal social structure? Oxf J Archaeol 31: 1-26. 
[57] Farizy C, David F, Jaubert J. 1994. Hommes et bisons du Paleolithique Moyen a Mauran. Paris: CNRS.

[58] Langley MC, Litster M. 2018. Is it ritual? Or is it children? Distinguishing consequences of play from ritual actions in the Palaeolithic archaeological record. Curr Anthropol 59: 616-643.

[59] Hawcroft J, Dennell R. 2000. Neanderthal cognitive life history and its implication for material culture. In: Sofaer Derevenski J, editor. Children and material culture. London: Routledge. p 89-99.

[60] de la Torre I, Martínez-Moreno J, Mora R. 2013. Change and stasis in the Iberian Middle Paleolithic: considerations on the significance of Mousterian technological variability. Curr Anthropol 54: 320-336.

[61] Rossano, M. J. (2017). Cognitive fluidity and Acheulean over-imitation. Cambridge Archaeological Journal, 27, 495-509.

[62] Lucas CG, Bridgers S, Griffiths TL, et al. 2014. When children are better (or at least more openminded) learners than adults: Developmental differences in learning the forms of causal relationships. Cogn 131: 284-299.

[63] Gopnik A, Griffiths TL, Lucas CG. 2015. When younger learners can be better (or at least more open-minded) than older ones. Curr Direct Psychol Sci 24: 87-92.

[64] Riede, F, Johannsen NN, Homberg A, et al. 2018. The role of play objects and object play in human cognitive evolution and innovation. Evol Anthropol 27: 46-59. 
[65] Tomasello M. 2000. The item-based nature of children's early syntactic development. Trends Cogn Sci 4: 156-163.

[66] Perfors A, Tenenbaum JB, Regier T. 2011. The learnability of abstract syntactic principles. Cogn 118: 306-338.

[67] Carruthers P. 2002. Human creativity: its cognitive basis, its evolution and its connections with childhood pretense. Brit J Phil Sci 53: 225-249.

[68] Nowell A. 2015. Children, metaphorical thinking and Upper Paleolithic visual cultures. Childhood Past 8: 122-132.

[69] Nowell A. 2016. Childhood, Play and the Evolution of Cultural Capacity in Neanderthals and Modern Humans. In: Haidle M, Conard N and Bolus M, editors. The nature of culture. Dordrecht: Vertebrate Paleobiology and Paleoanthropology. Springer. p 87-97.

[70] Burghardt GM. 2011. Defining and recognizing play. In: Nathan P and Pellegrini AD, editors. The Oxford Handbook of the Development of Play. Oxford: Oxford University Press.

[71] Deacon TW. 2010. A role for relaxed selection in the evolution of the language capacity. Proc Natl Acad Sci 107: 9000-9006.

[72] Lillard AS. 2017. Why Do the Children (Pretend) Play? Trends Cogn Sci 21: 826-834.

[73] Weisberg DS. 2015. Pretend play. Wiley Interdisc Rev Cogn Sci 6: 249-61. 
[74] Leslie AM. 1987. Pretence and representation: The origins of 'theory of mind'. Psych Rev 94: 412-426.

[75] Piaget J. 1962. Play, dreams, and imitation in childhood. New York: Norton.

[76] Belsky J, Most RK. 1981. From exploration to play: A cross-sectional study of infant free play behavior. Dev Psychol 17: 630-639.

[77] Orr E, Geva R. 2015. Symbolic play and language development. Infant Behav Dev 38: 147-161.

[78] Greenfield PM. 1991. Language, tools and brain: the ontogeny and phylogeny of hierarchically organized sequential behavior. Brain Behav Sci 14: 531-595.

[79] Kolodny O, Edelman S. 2018. The evolution of the capacity for language: The ecological context and adaptive value of a process of cognitive hijacking. Phil Trans R Soc B Biol Sci 373: 20170052.

[80] Bruner J. 1983. Play, thought, and language. Peabody J Educ 60: 60-69.

[81] Levy AK. 1984. The language of play: The role of play in language development: A review of literature. Early Child Dev Care 17: 49-61.

[82] Quinn S, Donnelly S, Kidd E. 2018. The relationship between symbolic play and language acquisition: A meta-analytic review. Dev Rev 49: 121-135. 
[83] Lewis V, Boucher J, Lupton L, et al. 2000. Relationships between symbolic play, functional play, verbal and non-verbal ability in young children. Int J Lang Comm Disord 35: 117-27.

[84] Farver, J.A.M., 1992. Communicating shared meaning in social pretend play. Early Childhood Research Quarterly, 7(4), pp.501-516.

[85] Nicely P, Tamis-LeMonda CS, Bornstein MH. 1999. Mothers' attuned responses to infant affect expressivity promote earlier achievement of language milestones. Infant Behav Dev 22: 557-568.

[86] Kempe V, Brooks PJ, Mironova N, et al. 2007. Playing with word endings: Morphological variation in the learning of Russian noun inflections. Br J Dev Psychol, 25: 55-77.

[87] Kempe V, Brooks PJ, Pirott L. 2001. How can child-directed speech facilitate the acquisition of morphology? In: Almgren M, Barreña A, Ezeizabarrena M-J, et al., editors. Proceedings of the VIIIth International Congress for the Study of Child Language. Medford: Cascadilla Press. p 1237-1247.

[88] Bebout J, Belke E. 2017. Language play facilitates language learning: Optimizing the input for gender-like category induction. Cogn Res: Prin Imp 2: 11.

[89] Obermeier C, Menninghaus W, von Koppenfels M, et al. 2013. Aesthetic and emotional effects of meter and rhyme in poetry. Front Psychol 4: 1-10.

[90] Ludke KM, Ferreira F, Overy K. 2014. Singing can facilitate foreign language learning. Memory Cogn 42: 41-52. 
[91] Thiessen ED, Saffran JR. 2009. How the melody facilitates the message and vice versa in infant learning and memory. Ann New York Acad Sci 1169: 225-233.

[92] Bjorklund DF, Beers C. 2016. The adaptive value of cognitive immaturity: Applications of evolutionary developmental psychology to early education. In: Geary DC and Berch DB, editors. Evolutionary perspectives on child development and education. Cham: Springer. p 3-32.

[93] Christiansen MH, Chater N. 2016. The Now-or-Never bottleneck: A fundamental constraint on language. Behav Brain Sci 39:

[94] Gentner D, Namy LL. 2006. Analogical processes in language learning. Curr Direc Psychol Sci 15: 297-301.

[95] Bateson P. 2014. Play, playfulness, creativity and innovation. Animal Behav Cogn 1: 99-112.

[96] Pellegrini AD, Dupuis D, Smith PK. 2007. Play in evolution and development. Dev Rev 27: 261276.

[97] Legare CH, Nielsen M. Imitation and innovation: The dual engines of cultural learning. Trends in cognitive sciences. 2015 Nov 1;19(11):688-99.

[98] Raviv L, Arnon I. 2018. Systematicity, but not compositionality: Examining the emergence of linguistic structure in children and adults using iterated learning. Cognition 181:160-73.

[99] Kempe V, Gauvrit N, Gibson A, Jamieson M. 2019. Adults are more efficient in creating and transmitting novel signalling systems than children. Journal of Language Evolution 4(1): 44-70. 
[100] Labov W. 2001. Principles of linguistic change Volume 2: Social factors. Language in Society. Oxford: Blackwell.

[101] Fitch WT. 2009. Prolegomena to a science of biolinguistics. In: Röska-Hardy LS and NeumannHeld EM, editors. Learning from animals? Examining the nature of human uniqueness. New York: Psychology Press. p 15-44.

[102] Piantadosi ST, Tily H, Gibson E. 2012. The communicative function of ambiguity in language. Cognition 122: 280-291.

[103] Haiman J. 2010. The creation of new words. Linguistics 47: 549-572.

[104] Hart BL. 1985. The behavior of domestic animals. New York: W.H. Freeman and Company.

[105] Himmler BT, Stryjek R, Modlinska K, et al. 2013. How domestication modulates play behavior: a comparative analysis between wild rats and a laboratory strain of Rattus norvegicus. J Comp Psychol 127: 453-64.

[106] Karlenberg SM, Wrangham RW. 2010. Sex differences in chimpanzees' use of sticks as play objects resemble those of children. Curr Biol 20: 1067-1068.

[107] Baxter JE. 2005. The archaeology of childhood. Children, gender, and material culture. New York: Altamira Press. 
[108] Stapert D. 2007. Youngsters knapping flint near the campfire: an alternative view of Site K at Maastricht-Belvédère (The Netherlands). “A refitter's paradise". Archäologisches Korrespondenzblatt 37: 19-35.

[109] Bodu P. 1990. L'application de la méthode des remontages à l'étude du matériel lithique des premiers niveaux châtelperroniens d'Arcy-sur-Cure. In: Farizy C, editor. Paléolithique Moyen recent et Paléolithique Supérieur Ancien en Europe. Nemours: Musée de Préhistoire d'Ile de France. p 30912.

[110] Duhard J-P. 1993. Upper Palaeolithic figures as a reflection of human morphology and social organization. Antiquity 67: 83-91.

[111] Langley MC. 2017. Magdalenian children: Projectile points, portable art, and playthings. Oxf J Archaeol 37: 1-22.

[112] White R. 2003. Prehistoric art: The symbolic journal of humankind. New York: Abrams.

[113] Van Gelder L. 2015. Counting the children: the role of children in the production of finger flutings in four Upper Palaeolithic caves. Oxf J Archaeol 34: 119-38.

[114] Arias P. 2009. Rites in the dark? An evaluation of the current evidence for ritual areas at Magdalenian cave sites. World Archaeol 41: 262-94.

[115] Ucko P, Rosenfeld A. 1967. Palaeoltihic cave art. New York: McGraw Hill. 
[116] Pigeot N. 1990. Technical and social actors: flintknapping specialists and apprentices at Magdalenian Etoilles. Archaeol Rev Camb 91: 126-41.

[117] Grimm L. 2000. Apprentice flintknapping: relating material culture and social practice in the Upper Palaeolithic. In: Sofaer Derevinski J., editor. Children and material culture. London: Routledge. p 53-71.

[118] Fritz C, Tosello G, Conkey MW. 2015. Reflections on the identities and roles of the artists in European Palaeolithic societies. J Archaeol Meth Theory 23: 1307-32.

[119] Rivero O. 2016. Master and apprentice: evidence of learning in Palaeolithic portable art. J Archaeol Sci 75: 89-100.

[120] Gerasimov MM. 1935. Raskopki plaeoliticheskoi stoianki v sele Mal'ta. Izvestiia Gosdarstvennoi Akademii Istorii Material'noi Kul'tuy 118: 78-124.

[121] Akazawa T, Muhensen S, Dodo Y, et al. 1995. Neanderthal infant burial from the Dederiyeh Cave in Syria. Paléorient 21: 77-86.

[122] Derevianko A 1998. The Paleolithic of Siberia. New Discoveries and Interpretations. Urbana: University of Illinois Press. 


\section{FIGURE LEGENDS}

Figure 1: An outline of the genetic, physiological, and behavioral changes that can account for our language-readiness and the evolution of complex languages in our species.

Figure 2: Buried children remain the main form of evidence for investigating Pleistocene childhoods, and while frequently buried with extensive arrays of grave goods, these artifacts may never have been used by the child before their death. (Left) Burial of a 3-4 year old and 1-2 year old children at the Siberian site of Mal'ta (Redrawn after Gerasimov $1935^{120}: 119$, Fig. 36); (Right) Burial of a 2 year old child at Dederiyeh Cave in Syria (Redrawn after Akazawa et al., 1995 ${ }^{121}$ ). (1 \& 2) Mammoth ivory diadem; (3) ivory necklace; (4) stone knife; (5) ivory disc; (6) ivory flying bird figurine; (7) ivory unbarbed point; (8 \& 9) stone tools; (10) limestone block; (11) flint tool.

\section{Box 1: Artifacts most likely to represent Pleistocene children's toys.}

Recent and modern hunter-gatherer children the world over play with the same types of playthings: miniature weapons, miniature tools, musical instruments, collectibles, and dolls or figurines. ${ }^{69}$ Figurines were/are made both by children and by adults for children. The raw materials used to make these toys depended on what was commonly available, and their forms were dictated by species common to their environment. ${ }^{69}$ From this information we can be confident that Pleistocene Modern Human children (at least) made or had made for them, human dolls and/or animal figurines to include in their games. Such items are a feature of Upper Palaeolithic Europe (in particular), and it is likely that at least some examples recovered by archaeologists constitute children's toys. ${ }^{69}$

Shown here are a selection of mammoth ivory, reindeer antler, and clay (no. 13) figurines from the Upper Palaeolithic Siberian site of Mal'ta which are consistent with ethnographic parallels in children's material culture (After Derevianko ${ }^{122}$ : Figs 44, 130, 131, 132, 134). Further analysis is required to ascertain if they may have been used in this fashion, or if they represent adult ritual actions as frequently assumed. 